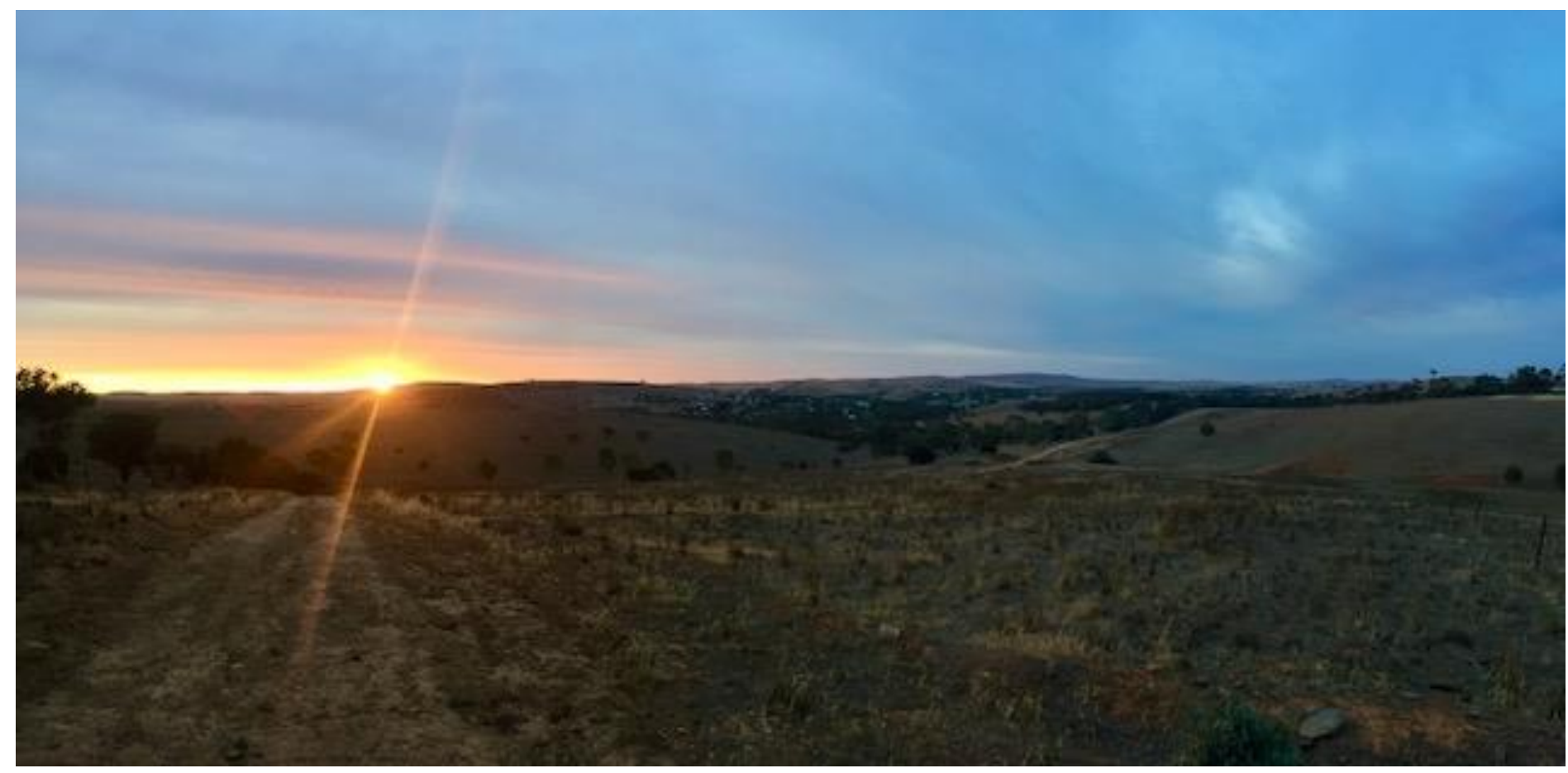

\title{
Virtual Triage and Teletriage in Rural Canada and Australia
}

A Rapid Review

Jaymie Barnabe, Sam Petrie, and Paul Peters

DOI: $10.22215 /$ sdhlab/2020.2 


\section{Suggested Citation}

Barnabe J., Petrie S., \& P. Peters. 2020. Virtual Triage and Teletriage in Rural Canada and Australia: A Rapid Review. Spatial Determinants of Health Lab Ottawa, ON. doi: 10.22215/sdhlab/2020.2.

\section{About the Spatial Determinants of Health Lab}

Work in the Spatial Determinants Lab focusses on the study of inequities in human health outcomes and determinants of health in small places and small spaces. Despite decades of universal healthcare for many countries around the world, there still remain pronounced inequities in the social determinants of health, health outcomes, and in environmental exposures. These systemic differences are manifest between social groups and across

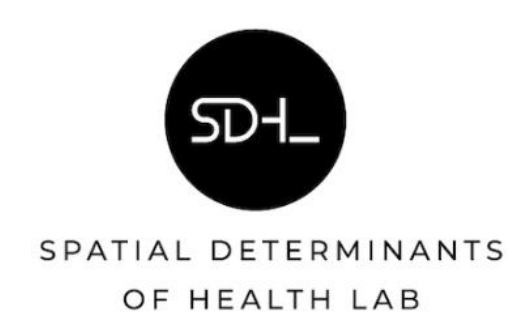
a range of factors such as income, education, and ethnicity. At the same time, health inequities are spatially evident, with differences between countries, regions, communities, and neighbourhoods. Understanding the relationships between social processes, geography, and human health is the focus of our Lab.

We are located in the Department of Health Sciences, Carleton University, Canada.

\section{carleton.ca/determinants/}

Funding for this rapid review was provided through the Free Range International Knowledge Exchange project funded by the Social Sciences and Humanities Research Council (SSHRC) of Canada.
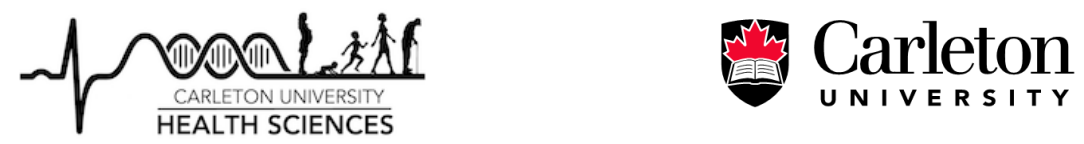


\section{Contents}

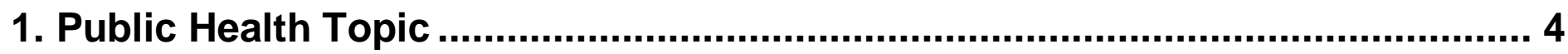

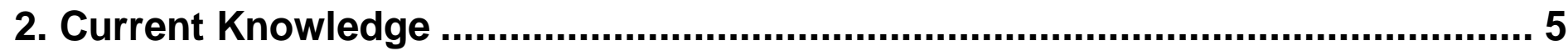

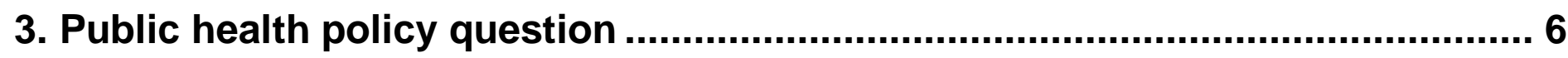

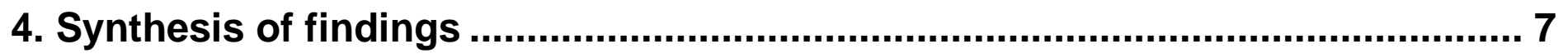

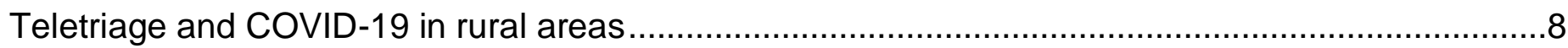

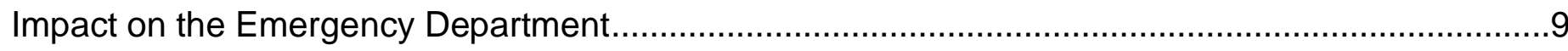

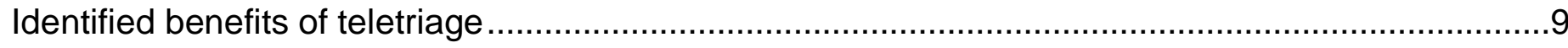

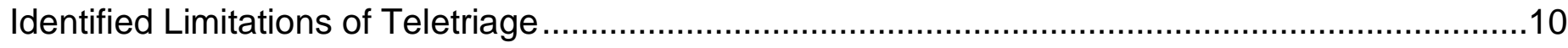

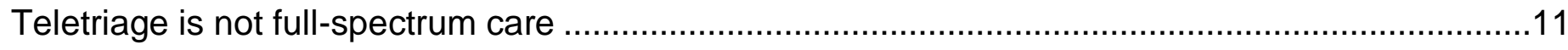

5. Implications for organizations ..................................................................12

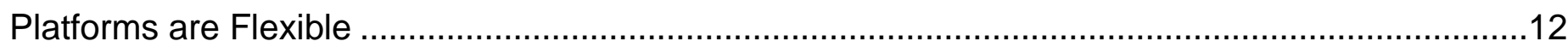

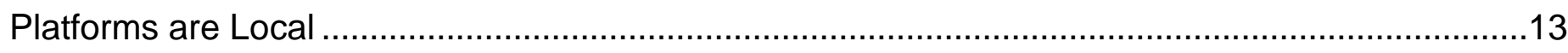

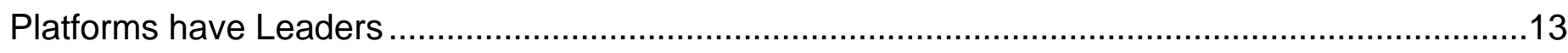

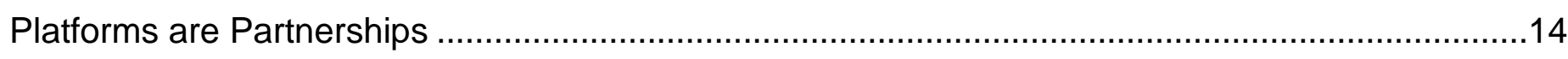

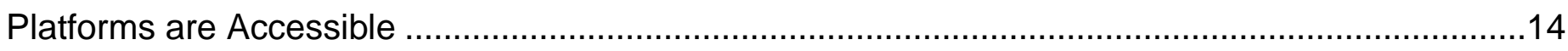

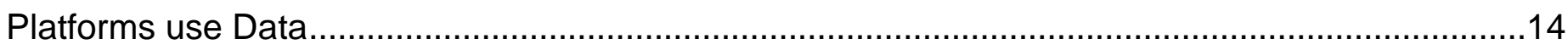

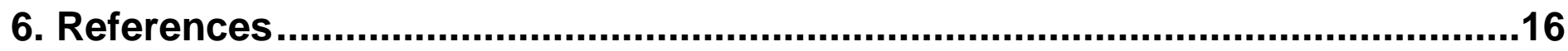

7. Methodological Appendix ..............................................................................

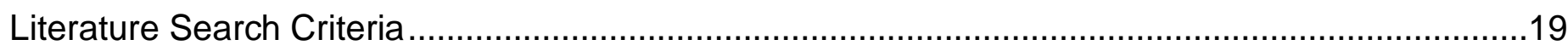

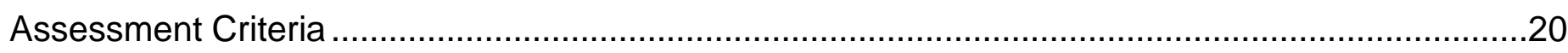

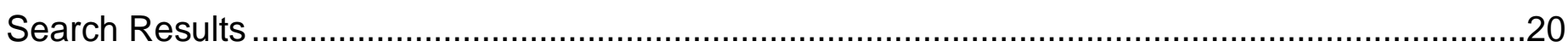

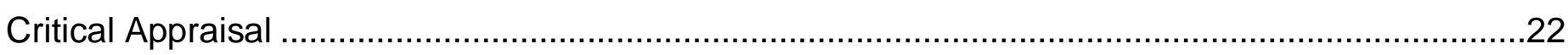

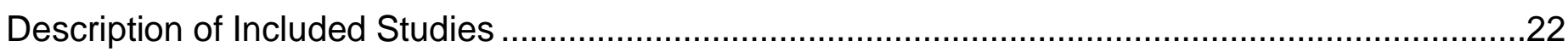

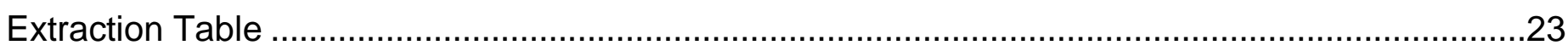




\section{Key Evidence:}

- Telephone triage (teletriage) has been slow to expanded in Canada and Australia.

- Teletriage is effective, safe, with high levels of reported patient satisfaction.

- Teletriage can provide an alternative to primary acute care when not available.

- Virtual triage is recent with most new platforms implemented due to the COVID-19 pandemic.

- Integration of video creates multiple layers of care, further improving effectiveness.

- Many of the limitations of tele- and virtual triage are related to existing inequalities in rural areas.

- Tele- and virtual systems can be effective at deferring patients from emergency departments.

\section{Policy Recommendations:}

- Platforms need to be flexible, responsive, and tailored to regional circumstances

- Successful platforms are locally-based

- Leadership across stakeholders is essential to success

- Platforms are partnerships and collaborations

- Advertising and messaging are important

- Platforms use and create data, which must be analysed continuously 


\section{Public Health Topic}

Health care services and healthcare infrastructure in rural areas is continuously adapting in to meet the needs of rural and remote populations. Rural populations are unique and diverse, where there is a diversity of individuals within communities, and an equivalent diversity between communities. There are documented differences in health behaviours, health literacy, perceived health, and health outcomes between and within rural regions and rural communities. ${ }^{1}$ While geographic accessibility is often considered the primary driver, differences go beyond distance and include elements of demographic change, economic restructuring, and continued reductions in health and services. ${ }^{2}$

The features of rural health care delivery are further underscored in the wake of the COVID-19 global health pandemic, a rapidly evolving situation which is undoubtedly putting pressure on already strained rural emergency departments (ED). In attempts to alleviate strain on front-line health provision and ensure the safety of the public, many healthcare facilities have rapidly implemented or have scaled-up eHealth solutions such as virtual triage and urgent care systems. These are virtual (virtual triage) or telephone systems (teletriage) in which patients can contact a physician or other healthcare professional who will guide them to appropriate care. The objective of these interventions is most often to reduce the overall number of in-person visits to EDs, potentially tackling ED overcrowding and misuse. 3 


\section{Current Knowledge}

Overcrowding, long wait times, and lack of resources is a persistent issue in countries with publicly guaranteed health systems, with EDs being disproportionately affected. ${ }^{3}$ This is especially prevalent in rural Canada and Australia, where rural healthcare access and resources are limited.4,5 Although it is a complex problem, one of the main contributing factors to this pressure is the growing number of patients presenting to EDs with non-urgent complaints, many of whom are seeking primary care. 6 Although seeking non-urgent care from the emergency department is seen as inappropriate to health system planners, it is often the only choice rural patients have. 4 Over 4.7 million Canadians do not have a primary care provider and only $25.1 \%$ report they have a usual place of care such as an urgent care clinic, a luxury that is hard to come by in rural areas. 7 A similar reality is seen in Australia, where access to general practitioners in regional or remote areas is limited, with many reporting visiting ED's because a general practitioner was not available. ${ }^{8}$

Initiatives such as telehealth and virtual visits have been suggested to bridge the gaps seen in rural healthcare and are part of broader eHealth initiatives that include electronic medical records, remote health monitoring, and other electronic health technologies. Identified benefits of using eHealth services for primary care provision include reducing the burdens that come with travelling long distances, increasing access to care, and cost savings across various domains. ${ }^{9}$ Despite perceived benefits, implementation is often non-existent, difficult, or slow. Cost, technological issues, and slow acceptance by providers is a recurring issue for successful long-term eHealth implementation.9,10

Teletriage and virtual triage are eHealth initiatives proposed to mitigate rural healthcare gaps. Teletriage is the use of telephone conferencing services to guide patients to appropriate care based on patient presentation, the urgency of the condition, and the policy of the organization. Virtual triage is where secure video connections are integrated with secure voice. Various telephone triage initiatives have been slowly developed and implemented across Canada, and Australia. ${ }^{11}$ Despite the evidence of success with teletriage, virtual and video integration with these systems has been met with resistance, with few adopting it.10,12,13 However, amid the COVID-19 pandemic, Canadian and Australian healthcare providers have been advised to provide virtual care where possible, resulting in the rapid creation and scaling up of exiting teletriage platforms and integration of virtual triage. 5,14 


\section{Public health policy question}

This review evaluates current teletriage and virtual triage systems and provides guidance on the effectiveness and sustainability of triage systems implemented or modified in the wake of the COVID19 pandemic. The review also provides evidence for how these systems can reduce inequities in access to care for rural residents in Canada and Australia.

Evidence was synthesized by employing a mixed-methods rapid review approach ${ }^{15}$, including:

1. Synthesis and review of Canadian and Australian teletriage and virtual triage programs;

2. A literature review consisting of peer-reviewed studies, systematic reviews of peer-reviewed trials, meta-analyses, and an exploration of grey literature (see Appendix for details); and,

3. Interviews with key stakeholders with extensive rural eHealth experience. 


\section{Synthesis of findings}

Three primary applications of teletriage were identified in the available literature:

1. Health hotlines that provide information only;

2. Teletriage services that provide after-hour care, health advice, self-care instructions, and recommendations as to which types of health care should be accessed; and,

3. Teletriage services that book and provide formal appointments with a physician or other healthcare professional via a virtual telephone or video-consultation visit.

Overall, extensive research was found regarding telephone triage systems in Australia and Canada. Notably, there is little evidence in the academic literature of Canadian and Australian triage systems being integrated with telehealth and videoconferencing until recently, with the most extensive developments seen with the onset of the pandemic.

Given the novelty of virtual triage, there is little published research outlining and studying the longer-term effectiveness or videoconferencing and teletriage in rural Australian and Canadian contexts.

\section{Teletriage in Canada}

In Canada, each of the 13 provinces and territories has responsibility for service provision and maintenance of teletriage systems. Most jurisdictions except for Prince Edward Island, Yukon Territory, and Northwest Territories provide province-wide teletriage services where individuals talk over the phone with trained professionals. ${ }^{16}$ Video conferencing in general within the healthcare field is evident in all provinces, but it is limited in Newfoundland and Labrador as well as PEI. In some jurisdictions, the teletriage service expands care to allied health professionals such as contact with pharmacists regarding advice about medications, or advice from a dietician. ${ }^{17}$ However, there is little evidence of video consultations being integrated with larger-scale provincial teletriage systems. ${ }^{16}$

The onset of COVID-19 has seen the expansion and increased usage of teletriage and virtual triage services for primary care provision. ${ }^{18,19}$ This is despite the fact that stakeholders in rural communities felt provincial resources have fallen short at providing personalized care tailored to regional and local 
circumstances. With the increase in funding for virtual interventions, Canada has seen the emergence of only two locally-based teletriage systems, one in as little as 12 days. ${ }^{20}$

\section{Teletriage in Australia}

An example of a standardized telenursing triage service is HealthDirect, that was first introduced in May 1999 in Western Australia. ${ }^{21}$ Since its introduction, the program has expanded with Victoria and Queensland also offering state-funded telephone helplines. ${ }^{21}$ Over the years, the health line has expanded to offer subspecialty of services such as the 'after-hours GP helpline,' which connects patients with a general practitioner and the Pregnancy and Baby telephone health-line which offers guidance to parents or parents-to-be. ${ }^{22,23}$

In March 2020, a targeted action plan was initiated by the Australian government department of health in response to the COVID-19 pandemic. ${ }^{24}$ This led to a response of 2.4 billion to fund a wholepopulation model of telehealth such as using telephone or video consultations and establishment of call centres to triage people with fever or respiratory symptoms, provide advice and direct them to the most appropriate health services. Calls to HealthDirect dramatically increased and telehealth is now available countrywide. ${ }^{24}$

\section{Teletriage and COVID-19 in rural areas}

Rural regions pose increased challenges to the delivery of health services due to geographical isolation and access, persistently lower centralized funding, different socioeconomic and health profiles of residents, and a general lack of access to family physicians. ${ }^{20}$ These well-documented challenges have been further highlighted by the circumstances surrounding the COVID-19 pandemic.

At the onset of the COVID-19 pandemic, physical assessment centres were established in urban centres to test for COVID-19 in an out-of-hospital setting. Contrarily, a single assessment centre in rural areas is unsuitable to serve the needs of the population adequately. ${ }^{20}$ Placing an assessment centre in only one area would lead to inequity for other areas. ${ }^{20}$ However, rural establishments do not have the resources to maintain, staff and stock multiple testing centres with appropriate personal protective equipment. Teletriage was suggested not only to provide urgent and acute episodic care remotely but as an alternative mean to aid in the diagnosis and surveillance of COVID-19. ${ }^{20,23-25}$ 


\section{Impact on the Emergency Department}

Existing literature presents mixed reviews on the impact of teletriage systems on EDs. Some published studies demonstrate that teletriage interventions have moderate to substantial reductions of deferrals in ED visits and hospital readmissions, especially for older and chronic patients and parents with young children. ${ }^{21,26-28}$ This effect was further demonstrated when teletriage services offered multiple layers of care, such as integrating virtual assessments and appointments by physicians or nurse practitioners. ${ }^{20}$

On the contrary, some studies show that a high number of patients with lower urgency conditions are still advised to attend by teletriage professionals. ${ }^{21}$ This suggests there might be patients referred to ED by call lines which could potentially be managed outside of an emergency setting. ${ }^{21}$ These systems are typically based on automated algorithm systems, delivered by non-clinicians such as clerical staff, or teletriage systems that deliver care to large geographical areas (i.e. provincial) and typically staffed by those with poor triage knowledge of specific areas. ${ }^{17,21}$ This shows that teletriage systems can be effective at deferring patients away from the ED, but there is room for further improvement. ${ }^{28}$ Further research is needed to understand the overall impact of teletriage on EDs and the economic impacts on healthcare systems as a whole.

\section{Identified benefits of teletriage}

Studies which conducted surveys of patients who used a teletriage service reported high rates of

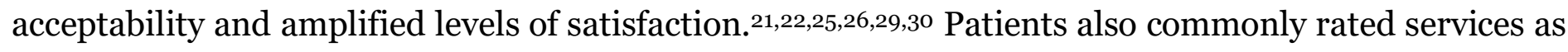
helpful and valuable. ${ }^{21,22}$ Other patient-reported benefits include providing emotional reassurance by providing immediate care in time of need and decreasing long travel times to care facilities.22,31 Due to its nature, teletriage can also significantly reduce waiting times to see a physician and receive the care and advice they need, reducing diagnostic delay.25,31,32 Teletriage also increases knowledge of available resources other than ED's, some of which patients never knew existed. ${ }^{22}$

Studies also reported a high level of safety in terms of triage decisions and patient outcomes. ${ }^{21,27,33}$ When looking at the appropriateness of triage advice, providers are more likely to err on the side of caution rather than under-refer. ${ }^{33}$ For systems integrated with video consultations, virtual visits performed equally or even better than outpatient appointments. 34 
Teletriage is also flexible and can be easily customized to provide various domains of care.25 For example, some studies suggest integrating teletriage with remote in-home patient monitoring can further provide care, reduce ED visits and hospital admissions, and improve the ability of patients to self-manage at-home. ${ }^{20,26,35}$

Teletriage also provides benefits considering the COVID-19 pandemic. Teletriage eliminates person-toperson interaction, reducing exposure risks to healthcare workers and other patients ${ }^{20,24,25}$ This also preserves personal protective equipment (PPE), conserving critically low resources. ${ }^{20,25}$

\section{Identified Limitations of Teletriage}

One of the most consentient reported limitations was lack of patient awareness of the service, drastically limiting its usefulness in the healthcare system.17,21,22,27,36 Also, of patients who knew about the service, some felt the service might not be helpful, often because of a misunderstanding of the service. ${ }^{21}$ This reflects the lack of advertisement and communication between partners in the healthcare system.

Furthermore, many teletriage services offered throughout Australia and Canada are telephone-only interactions. However, telephone-only triage falls short. ${ }^{22}$ Verbal communication cannot reflect the complexity of some health presentations, as there are other visible indicators. 37 Telephone interactions also may lead to bias. For example, patients may be in a non-ideal environment, or forget to report key symptoms, giving a skewed perspective for the provider. 37 This can not only minimalize the impact teletriage has on deferring patients from the emergency department but can affect its safety due to possible underestimation of conditions, leading to adverse patient outcomes.

However, integrating video consultations poses concerns regarding patient privacy and confidentiality. ${ }^{30}$ For example, patient details may be inadvertently disclosed if teletriage interactions are not delivered in private areas. ${ }^{38}$ In addition, using video technology requires patients to have access to a device and be able to access the software the provider is using. This raises concerns regarding technology literacy, especially of older generations. ${ }^{30}$

Some concerns are due to the lack of resources and inequities faced in rural areas. 39 For example, it is well known that rural areas face Internet and broadband difficulties, making it difficult to implement video and virtual components in these areas. ${ }^{17,30,31,38}$ It was also found that patient compliance when advised to go to the emergency department or seek physician appointment is lower in rural areas, 
overall reflecting barriers such as overcrowding and lack of resources in that area.40,41 There are also concerns regarding funding and staffing. Rural practices are at a disadvantage as it costs more to implement individualized and well-developed systems in isolated regions. 17,25,32 Rural projects are dependent on purpose-specific funding supplementation and incentives. ${ }^{17}$ Also, physician recruitment in rural areas is already a struggle, and implementation of triage services does not improve this. ${ }^{17,20,31}$

\section{Teletriage is not full-spectrum care}

Despite its nature of connecting patients with physicians and nurses, teletriage does not replace fullspectrum primary care. ${ }^{20,22,36}$ Benefits of teletriage are counteracted if patients abuse the system by utilizing teletriage instead of their primary care provider, creating poor outcomes and redundancy in care.32,36 Teletriage is designed to aid existing primary care by ensuring all have access to acute episodic care, especially for those who do not have contact with a general or family practitioner. ${ }^{20}$ 


\section{Implications for organizations}

Teletriage and virtual triage systems can involve adjustments of organizational, professional, clinical, and technological processes to provide adequate services within an integrated and coordinated health system. In addition, they are only effective at adequately deferring patients away from EDs if overtriage rates are low, but unsafe if under-triage rates are high. ${ }^{36}$

Existing literature suggests several critical factors for implementing and sustaining successful teletriage and virtual triage systems. The following recommendations outline policy and systemic shifts that are shown to be essential to make the system safe and reliable.

Table 1: Policy Recommendations for Teletriage and Virtual Triage Implementation

1. Platforms need to be flexible, responsive, and tailored to regional circumstances

2. Successful platforms are locally-based

3. Leadership across stakeholders is essential to success

4. Platforms are partnerships and collaborations

5. Advertising and messaging are important

6. Platforms use and create data, which must be analysed continuously

\section{Platforms are Flexible}

The needs of rural community are constantly changing, and COVID-19 has further highlighted the importance of flexibility in care delivery. Successful teletriage programs are established with appropriate yet flexible platforms to deliver sustainable care. ${ }^{25}$ Services and platforms must be able to adapt adequately, even to unforeseen applications. ${ }^{31}$ Teletriage systems that are more full-service will take longer to implement but offer flexibility and robust options to flex according to the needs of a community. ${ }^{25}$

When developing a platform, seamless access to a patients electronic medical record is recommended. ${ }^{25,27}$ This will combat redundancy in treatment, increase understanding of patients for personalized care, and aid in continuity of care of a patient. ${ }^{8}$ If broadband permits, triage systems should also incorporate video consultations make the service more effective as teletriage alone can fall 
short due to lack of visual cues. 37 Creating multiple layers of care by incorporating video consultations will further enhance the benefits of teletriage, such as reducing ED referrals.

\section{Platforms are Local}

Services that are situated locally provide better and more personalized care. ${ }^{17,42}$ Teletriage programs that cover large geographical areas are staffed by those with little knowledge of local service options and local contexts, which is problematic when referring patients to appropriate services in their area. ${ }^{17}$ Locally-based teletriage programs perform better not only because providers have increased knowledge of resources, but because they have increased motivation to assist those in their local community. ${ }^{42}$

\section{Platforms have Leaders}

There is continual examination surrounding appropriate staffing for teletriage systems. The only agreement between studies is that the utilization of clerical staff is not appropriate, even if adequately trained or closely adhering to well-developed software and algorithm systems. ${ }^{21,43}$ Not only is using inexperienced staff unsafe, it negatively impacts the effectiveness of teletriage programs as they have minimal ability to detect which cases require less urgent evaluation. ${ }^{21}$

Having previous experience in managing calls is key to providing confident and correct care. ${ }^{42}$ Teletriage for EDs should be operated by experienced staff such as emergency physicians, nurses, or nurse practitioners with telehealth experience. ${ }^{25}$ There is discrepancy in the literature whether nurses or physicians are the right option. One study found that nurses have the highest average appropriate referral rates, even when compared to physicians. 43 Yet another study determined nurse practitioner interactions overall out-perform both registered nurses and physicians. 33 A separate study determined physician-led calls were briefer, associated to significant reductions in ED referrals and had higher rates of concordance between call centre recommendation and patient action, compared to nurse-led calls. ${ }_{27}$ Overall, both types are effective in triaging patients to an appropriate venue of care without incurring adverse patient outcomes, but physicians expertise may bring additional efficiency in the triage of highrisk complaints. $27,33,43$ 


\section{Platforms are Partnerships}

The development and success of any project in the healthcare field relies on collaboration initiatives and partnerships between facilities. This collaboration allows for adequate support and communication of experience and tips on maintaining a successful project. ${ }^{31}$ Partnerships with other organizations also create multiple layers of care to expand the scope of teletriage or virtual triage and give multiple viable alternatives to ED care. ${ }^{20,27}$ For example, one teletriage program in Canada formed a partnership with community paramedics who are deployed if a home visit or diagnostic testing is needed, further expanding the scope of the service and preventing travel to a healthcare facility. ${ }^{20}$

\section{Platforms are Accessible}

As mentioned previously, the lack of awareness of teletriage services is a significant issue. To increase the effectiveness of teletriage services, officials should consider a broad publicity campaign. ${ }^{21}$ Platforms can be promoted through newsprint, billboards, social media, television, radio, public health units, and other healthcare facilities such as local pharmacies. ${ }^{20}$ These campaigns should aim to capture the attention of the entire population and ensure the purpose of teletriage is clearly articulated. ${ }^{21}$ Advertising may also combat the issue of those who are aware of the service but did not think it would be helpful, as it can clear any misunderstandings or preconceived notions that consumers may have. ${ }^{21}$

To further improve equity of teletriage and virtual triage services, it should be easily accessible to all populations with a convenient, toll-free contact method.29,44 Having separate numbers or contacts for teletriage options make the service difficult to access and creates confusion and inequality of service for patients. ${ }^{17,29}$

Teletriage and virtual triage systems should also be easily accessible and centralized for healthcare professionals. When each healthcare branch chooses a separate technology to provide care, rural doctors can struggle to maintain familiarity with each system. 45 Well integrated, centralized systems will allow for the collaboration of healthcare professionals to provide the best care. 45

\section{Platforms use Data}

In order to maintain a safe and viable system, data regarding teletriage and virtual triage interactions and patient outcomes should be rigorously collected and analyzed regularly. 39 This will allow for quality 
and clinical safety assurance, help to inform institutional guidelines and policies throughout the life of the project, and target initiatives to improve systems. ${ }^{31,38,40,42,46}$ It will also provide professional accountability, and help grow an evidence base to strengthen business models for increased investment and expansion. ${ }^{26,38}$ 


\section{References}

1. Peters PA. View of Population Change and Population Health: A Spatio-temporal Analysis of New Brunswick Communities. J New Brunswick Stud. 2017;8:87-109. Available from: https://journals.lib.unb.ca/index.php/JNBS/article/view/25881/30044

2. Peters PA. Broadening the narrative on rural health: from disadvantage to resilience. Univ Toronto Med J. 2019;96(2):41-3. Available from: http://utmj.org/index.php/UTMJ/article/view/1179

3. Alavi-Moghaddam M, Forouzanfar R, Alamdari S, Shahrami A, Kariman H, Amini A, et al. Application of Queuing Analytic Theory to Decrease Waiting Times in Emergency Department: Does it Make Sense? Arch Trauma Res. 2012;1(3):101-7.

4. Fleet R, Archambault P, Poitras J. Access to emergency care in rural Canada: should we be concerned? Can J Emerg Med. 2013;15(4):191-3.

5. Australian Institute of Health and Welfare. Rural \& Remote Health. 2019. Available from: https://www.aihw.gov.au/reports/rural-health/rural-remote-health/contents/rural-health

6. Grumbach K, Keane D, Bindman A. Primary care and public emergency department overcrowding. Am J Public Health. 1993;83:372-8. Available from: https://www.ncbi.nlm.nih.gov/pmc/articles/PMC1694659/

7. Statistics Canada. Primary health care providers, 2017. Ottawa, ON; 2019. Available from: https://www150.statcan.gc.ca/n1/pub/82-625-x/2019001/article/oooo1-eng.htm

8. Australian Bureau of Statistics. Patient Experiences in Australia: Summary of Findings, 2018-19. 2019. Available from: https://www.abs.gov.au/ausstats/abs@.nsf/mf/4839.0

9. LeBlanc M, Petrie S, Paskaran S, Carson DB, Peters PA. Patient and provider perspectives on eHealth interventions in Canada and Australia: a scoping review. Rural and Remote Health. 2020 Sep;20(3):5754. DOI: 10.22605/rrh5754.

10. Murray E, Burns J, May C, Finch T, O’Donnell C, Wallace P, et al. Why is it difficult to implement ehealth initiatives? A qualitative study. Implement Sci. 2011 Jan 19;6(1). Available from: https://implementationscience.biomedcentral.com/articles/10.1186/1748-5908-6-6

11. O'Hanley P. Telephone triage: the quiet revolution in Canada. Telemed J E Heal. 2004;10(1):109-11.

12. Bennett-Levy J, Singer J, DuBois S, Hyde K. Translating e-mental health into practice: What are the barriers and enablers to e-mental health implementation by aboriginal and torres strait islander health professionals? J Med Internet Res. 2017 Jan 1;19(1). Available from: /pmc/articles/PMC5266824/?report=abstract

13. Bello AK, Molzahn AE, Girard LP, Osman MA, Okpechi IG, Glassford J, et al. Patient and provider perspectives on the design and implementation of an electronic consultation system for kidney care delivery in Canada: A focus group study. BMJ Open. 2017 Mar 1;7(3):e014784. Available from: http://bmjopen.bmj.com/

14. The Royal College of Physicians and Surgeons of Canada. Telemedicine and virtual careguidelines (and other clinical resources for COVID-19). 2020. Available from: http://www.royalcollege.ca/rcsite/documents/about/covid-19-resources-telemedicine-virtual-care-e

15. Dobbins M. Rapid Review Guidebook. Hamilton, ON; 2017. Available from: https://www.nccmt.ca/tools/rapid-review-guidebook

16. Canada's Health Informatics Association. Canadian Telehealth Report. Toronto, ON; 2015. Available from: https://livecare.ca/sites/default/files/2015 TeleHealth-Public-eBook-Final-10-9-15-secured.pdf 
17. Armstrong K, Amoyal G, Jacups S, Verhoeven A, Healthcare A, Association H. Review of after-hours service models: Learnings for regional, rural and remote communities. Vol. 15, Australian health review : a publication of the Australian Hospital Association. Northern Queensland; 2016.

18. Renfrew County Virtual Triage and Assesment Center. 2020. Available from: https://rcvtac.ca/

19. CHEO. Emergency Department virtual care. 2020. Available from: https://www.cheo.on.ca/en/visiting-cheo/emergency-department-virtual-care.aspx

20. Fitzsimon J, Gervais O, Lanos C, Sullivan-Bentz M. Providing 24/7 healthcare for all dururing the COVID-19 pandemic. Canadian Family Physician. 2020. Available from: https://www.cfp.ca/news/2020/o6/12/06-10

21. Turbitt E, Freed GL. Use of a telenursing triage service by V ictorian parents attending the emergency department for their child's lower urgency condition. Emerg Med Australas. 2015;27(6):558-62. Available from: https://onlinelibrary.wiley.com/doi/abs/10.1111/1742-6723.12477

22. McKenzie R. Consumer awareness, satisfaction, motivation and perceived benefits from using an afterhours GP helpline-A mixed methods study. Aust Fam Physician. 2016;45(7):512. Available from: https://www.racgp.org.au/afp/2016/july/consumer-awareness,-satisfaction,-motivation-andperceived-benefits-from-using-an-after-hours-gp-helpline---a-mixed-methods-study/

23. Morony S, Weir K, Duncan G, Biggs J, Nutbeam D, Mccaffery KJ. Enhancing communication skills for telehealth: development and implementation of a Teach-Back intervention for a national maternal and child health helpline in Australia. BMC Health Serv Res. 2018;18(1):162. Available from: https://bmchealthservres.biomedcentral.com/articles/10.1186/s12913-018-2956-6

24. Desborough J, Hall Dykgraaf S, DeToca L, Davis S, Roberts L, Kelaher C, et al. Australia's national COVID-19 primary care response. Med J Aust. 2020;213(3):104-6.

25. Christianson J, Christianson E. White paper: Using Telehealth in the Emergency Department to Minimize Risk to Health Care Providers and Conserve Resources During the COVID-19 Response. Southlake, TX; 2020.

26. Gheorghiu B, Ratchford F. Scaling up the use of remote patient monitoring in Canada. Vol. 209, Stud. Health Technol. Informatics. IOS Press; 2015. p. 23-6.

27. Sax DR, Vinson DR, Yamin CK, Huang J, Falck TM, Bhargava R, et al. Tele-Triage Outcomes For Patients With Chest Pain: Comparing Physicians And Registered Nurses. Health Aff. 2018;37(12):19972004.

28. Nataraj J, Stempien J, Netherton S, Wahba MY, Oyedokun TO. Emergency department referrals from a provincial medical call centre: Is it more than just 1-80o-go-to-emerg? Can J Emerg Med. 2020 Mar 1 [cited 2020 Jul 23];22(2):241-4.

29. Elsom S, Sands N, Roper C, Hoppner C, Gerdtz M. Telephone survey of service-user experiences of a telephone-based mental health triage service. Int J Ment Heal Nurs. 2013;22(5):437-43.

30. Andrés SF, María FGR, Ana P, Marina V, Bernardo M, Janine S, et al. Teletriage Pilot Study (Strategy for Unscheduled Teleconsultations): Results, Patient Acceptance and Satisfaction. Stud Health Technol Inform. 2020;270:776-80. Available from: http://ebooks.iospress.nl/publication/54268

31. Alami H, Fortin J-P, Gagnon M-P, Pollender H, Têtu B, Tanguay F. The challenges of a complex and innovative telehealth project: A qualitative evaluation of the eastern Quebec telepathology network. Int J Heal Policy Manag. 2018;7(5):421-32.

32. Zhao P, Yoo I, Lavoie J, Lavoie BJ, Simoes E. Web-based medical appointment systems: a systematic review. J Med Internet Res. 2017;19(4):e134. Available from: https://www.jmir.org/2017/4/e134/

33. Hogenbirk JC, Pong RW. An Audit of the Appropriateness of Teletriage Nursing Advice. Telemed J eHealth. 2004;10(1):53-60. 
34. Long R, Heffernan C, Gao Z, Egedahl ML, Talbot J. Do "Virtual" and "Outpatient" public health tuberculosis clinics perform equally well? A program-wide evaluation in Alberta, Canada. PLoS One. 2015;10(12). Available from: https://journals.plos.org/plosone/article?id=10.1371/journal.pone.0144784

35. Ding X, Clifton D, Ji N, Lovell NH, Bonato P, Chen W, et al. Wearable Sensing and Telehealth Technology with Potential Applications in the Coronavirus Pandemic. IEEE Rev Biomed Eng. 2020; Available from: http://ieeexplore.ieee.org/stamp/stamp.jsp?tp=\&arnumber=9090987\&isnumber $=4664313$

36. Çakıcı ÖE, Mills AF. Calling for Care? The Risky Proposition of Teletriage in Healthcare Demand Management. 2017. Available from: http://public.kenan-flagler.unc.edu/2017msom/MSOM and SIG Program/Track 7/D/MSOM2017_3_0369.pdf

37. Beks H, Healey C, Schlicht KG. "When you're it": a qualitative study exploring the rural nurse experience of managing acuta mental health preseantations. Rural Remote Health. 2018;18(3):4616. Available from: https://www.rrh.org.au/journal/article/4616

38. Mazza D, Kermond S, Harris C. 'I'm just ringing for some advice...'--issues concerning GP advice lines. Aust Fam Physician. 2006;35(1-2):61-2.

39. Ellis I, Kelly K. Health infrastructure in very remote areas: An analysis of the CRANA Bush Crisis Line database. Austr J Rural Heal. 2005;13(1):1-2.

40. de Coster C, Quan H, Elford R, Li B, Mazzei L, Zimmer S. Follow-through after calling a nurse telephone advice line: A population-based study. Fam Pr. 2010;27(3):271-8.

41. Tran DT, Gibson A, Randall D, Havard A, Byrne M, Robinson M, et al. Compliance with telephone triage advice among adults aged 45 years and older: An Australian data linkage study. BMC Heal Serv Res. 2017;17(1):512.

42. Knight KM, Kenny A, Endacott R. Gaps in governance: protective mechanisms used by nurse leaders when policy and practice are misaligned. BMC Heal Serv Res Res. 2015;15:145. Available from: https://www.ncbi.nlm.nih.gov/pmc/articles/PMC4396727/

43. Wheeler SQ, Greenberg ME. Safety of Clinical and Non-Clinical Decision Makers in Telephone Triage: A Narrative Review Journal of Telemedicine and Telecare. J Telemed Telecare. 2015;21(6):305-22.

44. Ahmad F, Norman C, O'Campo P. What is needed to implement a computer-assisted health risk assessment tool? An exploratory concept mapping study. BMC Med Informatics Decis Mak. 2012; 12:149.

45. Baker T. Providing a lifeline for rural doctors. Med J Aust. 2015;203(7):277.

46. Butler CW, Danby S, Emmison M, Thorpe K. Managing medical advice seeking in calls to Child Health Line. Sociol Health Illn. 2009;31(6):817-34. Available from: https://onlinelibrary.wiley.com/doi/abs/10.1111/j.1467-9566.2009.01179.x

47. Riva J, Malik K, Burnie S, Endicott A, Busse J. What is your research question? An introduction to the PICOT format for clinicians. J Can Chiropr Assoc. 2012;53(3):167-71. Available from: https://www.ncbi.nlm.nih.gov/pmc/articles/PMC3430448/

48. Critical Appraisal Skills Programme. CASP Checklists. [Internet] 2020. [Cited on Available from: https://casp-uk.net/casp-tools-checklists/ 


\section{Methodological Appendix}

\section{Literature Search Criteria}

Structured literature searches were performed using the bibliographic databases PubMed, Scopus, Web of Science, and Google Scholar. Key and MeSH terms related to teletriage and telehealth were used in combination with rural and location terms and their alternates. A full example with search terms used can be seen in

\section{Database: Scopus}

Date: 06/26/2020

Terms:

"eHealth" OR "telehealth" OR "tele-health" OR "tele-medicine" OR "telemedicine" OR "tele medicine" OR "tele communication" OR "online healthcare" OR "digital health" OR "mobile health" OR "mHealth"

AND

rural OR remote OR "region"”

AND

triage or "emergenc ${ }^{\star "}$ or "teletriage" or "tele-triage" or "eTriage" or "virtual triage" or "virtual clinic" or "Virtual emergency room" or "virtual emergency department"

AND
Canada OR Ontario OR "New Brunswick" OR "Nova Scotia" OR "Quebec" OR "Prince
Edward Island" OR Manitoba OR Saskatchewan OR Alberta OR Yukon OR "Northwest
Territories" OR Nunavut OR Australia OR "New South Wales" OR "South Australia" OR
Queensland OR "Northern Territory" or "Western Australia"

Results: 161

Figure 1.

Occasionally, it was found necessary to include additional studies that were not part of our core group of findings to lend authority, clarify terminology, and expand knowledge of the ever-changing healthcare system in the time of a pandemic. These articles were found in the references of core research papers or recommended by interviewed stakeholders. Stakeholders were rural eHealth professionals identified primarily by the project team. Stakeholders were identified and interviewed early in the review process to get insight into the topic and guide key questions. 
Database: Scopus

Date: 06/26/2020

Terms:

"eHealth" OR "telehealth" OR "tele-health" OR "tele-medicine" OR "telemedicine" OR

"tele medicine" OR "tele communication" OR "online healthcare" OR "digital health" OR "mobile health" OR "mHealth"

\section{AND}

rural OR remote OR "region"”

AND

triage or "emergenc*" or "teletriage" or "tele-triage" or "eTriage" or "virtual triage" or

"virtual clinic" or "Virtual emergency room" or "virtual emergency department"

AND

Canada OR Ontario OR "New Brunswick" OR "Nova Scotia" OR "Quebec" OR "Prince Edward Island" OR Manitoba OR Saskatchewan OR Alberta OR Yukon OR "Northwest Territories" OR Nunavut OR Australia OR "New South Wales" OR "South Australia" OR Queensland OR "Northern Territory" or "Western Australia"

Results: 161

\section{Figure 1: Full literature search example}

\section{Assessment Criteria}

Articles were scanned for relevance using a PICO framework. 47 The population of interest was rural communities in Canada and Australia served by triage systems, either before or in-response-to the COVID-19 pandemic. Interventions and outcomes of interest included subjective and objective analysis of triage networks in terms of safety, utilization, awareness, patient and provider perspectives, and overall impact domains of teletriage in rural or remote areas.

Only articles published after 2004 were included as articles published before this timeframe were unlikely to be representative and relevant to healthcare and technology observed today. Studies of patients being triaged in physical hospital settings, speciality related articles (such as dentistry and "telestroke"), and studies that took place outside of Canada and Australia with no application to these areas were excluded. Articles not written in English were also excluded. 


\section{Search Results}

The process of identifying eligible articles can be seen in

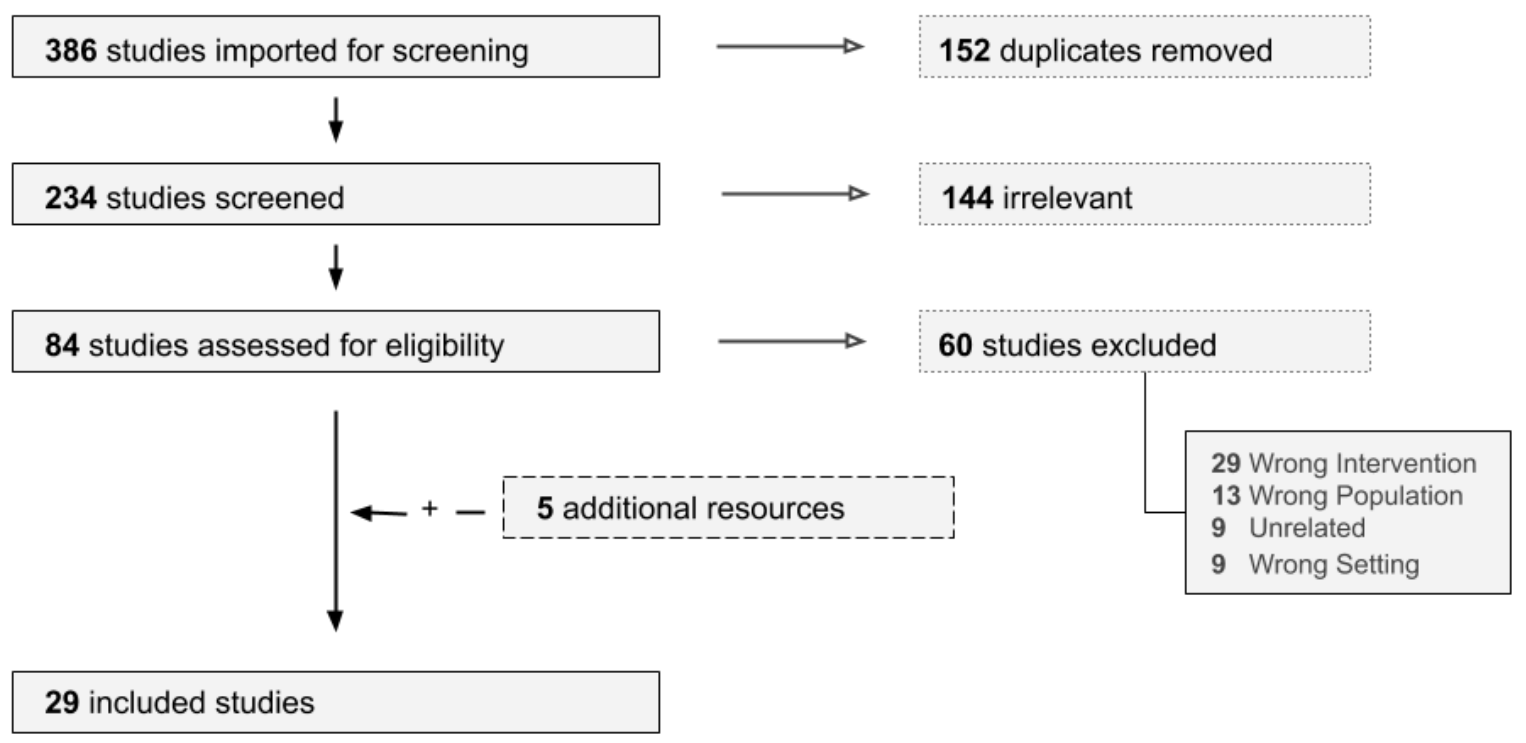

Figure 2. Bibliographic database results were saved and exported into the software Covidence for title and abstract screening. Unrelated articles, articles published before 2004, as well as 154 duplicates between databases were removed. This overall yielded 84 relevant studies. After reviewing and analyzing the relevant studies, 60 were removed for not meeting inclusion criteria. An additional five articles were identified and included in this review and were subject to the same critical appraisal and extraction process as other papers. 


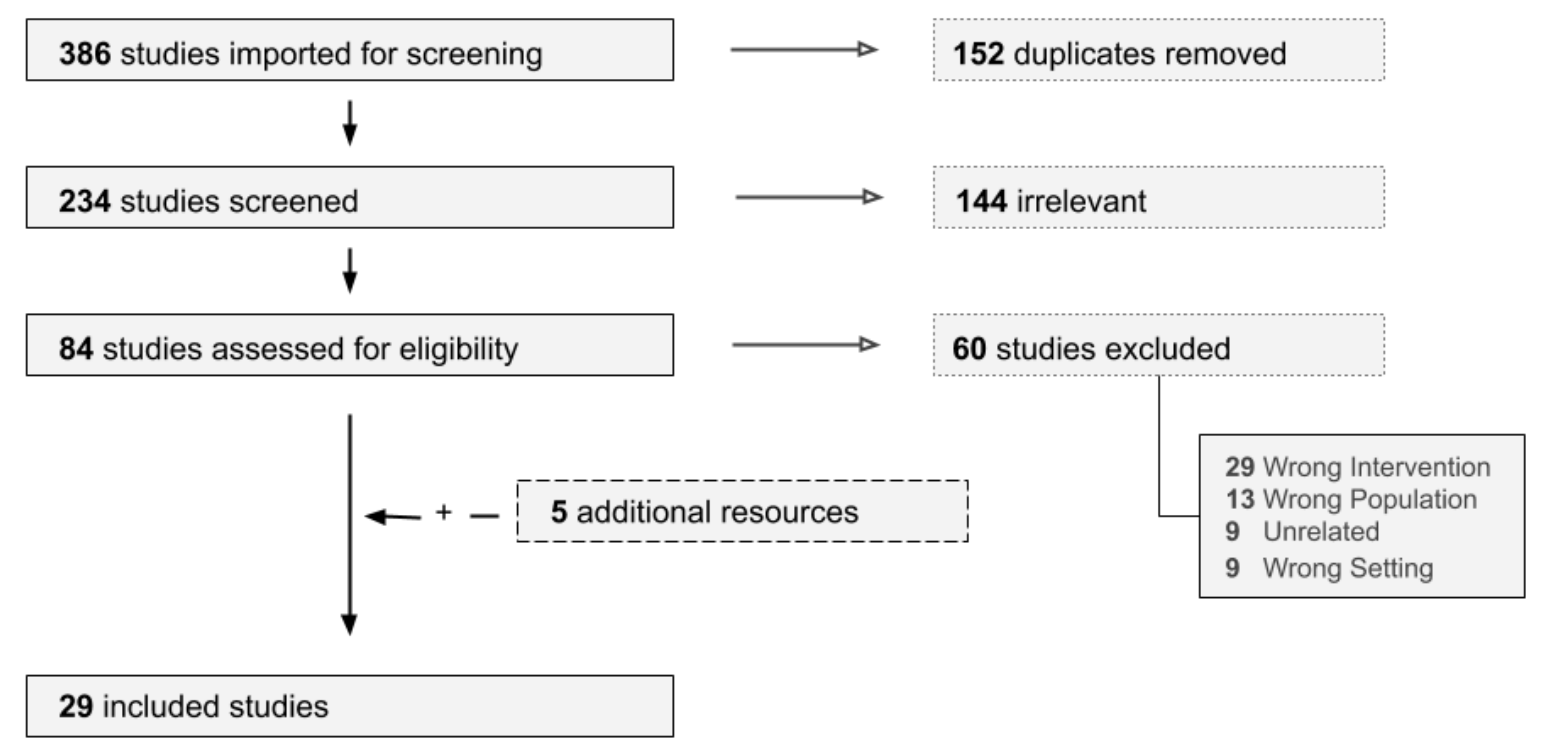

Figure 2 Flow diagram of search results and screening

\section{Exclusion Criteria}

Wrong setting (1) Study took place outside of Canada/Australia with no connections or applications to the population of interest. (2) Study only applies to those in urban centres with no application to rural areas

Wrong intervention: Study revolved around irrelevant subspecialties with no applications to area of study, i.e. telestroke articles

Wrong population: (1) Provider to provider telehealth consults/education. (2) Patient is being consulted by telehealth in the hospital with no application to outcomes of interest.

Unrelated: Has keywords and broad abstract but article is not relevant to paper; Very broad. 


\section{Critical Appraisal}

Quality of included studies was assessed using the Critical Appraisal Skills Programme (CASP) worksheets and checklists as outlined by the Oxford Centre for Triple Value Healthcare Ltd $(3 \mathrm{~V})$ portfolio ${ }^{48}$. After completing the respective worksheets for each article, they were appraised as being good, strong, or very strong. Due to the revolving situation regarding the pandemic and the novelty of teletriage, several articles were grey literature and could not be assessed using CASP. However, it was ensured that all articles were published by reputable sources and written by knowledgeable authors with first-hand experience in telehealth and teletriage applications.

\section{Strong/Very strong: 17}

\section{Good: 5}

\section{Grey: 7}

\section{Description of Included Studies}

Included literature on this topic is relatively new, with 22 articles (73\%) being published after 2015 and 26 articles (86\%) being published after 2010. Ten articles were based out of Canada, 12 were Australian, and two were based out of both countries. In this review, six articles were based out of other countries or were internationally based. These articles were used as an international comparison to our areas of interest and had results that were generalizable to Canada and Australia. Most studies included were rural-based, and all had results generalizable to rural areas. 


\section{Extraction Table}

\begin{tabular}{|c|c|c|c|c|c|}
\hline Citation Key & Article title & Appraisal Rating & Country & Qual/Quan & Rural \\
\hline $\begin{array}{l}\text { Gheorghiu } \\
2015\end{array}$ & $\begin{array}{l}\text { Scaling up the use } \\
\text { of remote patient } \\
\text { monitoring in } \\
\text { Canada }\end{array}$ & Strong & Canada & Qual/Quant & $\begin{array}{l}\text { Not explicitly } \\
\text { mentioned but } \\
\text { applicable }\end{array}$ \\
\hline Turbitt 2015 & $\begin{array}{l}\text { Use of a } \\
\text { telenursing triage } \\
\text { service by Victorian } \\
\text { parents attending } \\
\text { the emergency } \\
\text { department for } \\
\text { their child's lower } \\
\text { urgency condition }\end{array}$ & Very Strong & Australia & Qual/Quant & $\begin{array}{l}\text { Not explicitly } \\
\text { mentioned, but } \\
\text { applicable }\end{array}$ \\
\hline $\begin{array}{l}\text { Christianson } \\
2020\end{array}$ & $\begin{array}{l}\text { White paper: Using } \\
\text { telehealth in the } \\
\text { Emergency } \\
\text { Department to } \\
\text { Minimize Risk to } \\
\text { Health Care } \\
\text { Providers and } \\
\text { Conserve } \\
\text { Resources During } \\
\text { the COVID-19 } \\
\text { Response. }\end{array}$ & Grey & International & Qualitative & $\begin{array}{l}\text { Not explicitly } \\
\text { mentioned, but } \\
\text { applicable }\end{array}$ \\
\hline $\begin{array}{l}\text { McKenzie } \\
2016\end{array}$ & $\begin{array}{l}\text { Consumer } \\
\text { awareness, } \\
\text { satisfaction, } \\
\text { motivation and } \\
\text { perceived benefits } \\
\text { from using an after- } \\
\text { hours GP helpline- } \\
\text { A mixed methods } \\
\text { study }\end{array}$ & Very Strong & Australia & Qual/Quant & Included \\
\hline Zhao 2017 & $\begin{array}{l}\text { Web-based } \\
\text { medical } \\
\text { appointment } \\
\text { systems: a } \\
\text { systematic review }\end{array}$ & Strong & $\begin{array}{l}\text { Australia, } \\
\text { Canada }\end{array}$ & Qual/Quant & $\begin{array}{l}\text { Not explicitly } \\
\text { mentioned, but } \\
\text { applicable }\end{array}$ \\
\hline Andrés 2020 & $\begin{array}{l}\text { Teletriage Pilot } \\
\text { Study (Strategy for } \\
\text { Unscheduled } \\
\text { Teleconsultation) } \\
\text { Results, Patient } \\
\text { Acceptance and } \\
\text { Satisfaction }\end{array}$ & Strong & International & Qual/Quant & Included \\
\hline
\end{tabular}




\begin{tabular}{|c|c|c|c|c|c|}
\hline Cakici 2016 & $\begin{array}{l}\text { Calling for Care? } \\
\text { The Risky } \\
\text { Proposition of } \\
\text { Teletriage in } \\
\text { Healthcare } \\
\text { Demand } \\
\text { Management }\end{array}$ & Grey & International & Qualitative & Included \\
\hline Sax 2018 & $\begin{array}{l}\text { Tele-Triage } \\
\text { Outcomes For } \\
\text { Patients With } \\
\text { Chest Pain: } \\
\text { Comparing } \\
\text { Physicians And } \\
\text { Registered Nurses }\end{array}$ & Strong & International & Qual/Quant & $\begin{array}{l}\text { Not explicitly } \\
\text { mentioned, but } \\
\text { applicable }\end{array}$ \\
\hline Morony 2018 & $\begin{array}{l}\text { Enhancing } \\
\text { communication } \\
\text { skills for telehealth: } \\
\text { development and } \\
\text { implementation of } \\
\text { a Teach-Back } \\
\text { intervention for a } \\
\text { national maternal } \\
\text { and child health } \\
\text { helpline in Australia }\end{array}$ & Very Strong & Australia & Qualitative & $\begin{array}{l}\text { Not explicitly } \\
\text { mentioned, but } \\
\text { applicable }\end{array}$ \\
\hline $\begin{array}{l}\text { Armstrong } \\
2016\end{array}$ & $\begin{array}{l}\text { Review of after- } \\
\text { hours service } \\
\text { models: Learnings } \\
\text { for regional, rural } \\
\text { and remote } \\
\text { communities }\end{array}$ & Good & $\begin{array}{l}\text { Australia, } \\
\text { Canada }\end{array}$ & Qualitative & $\begin{array}{l}\text { Not explicitly } \\
\text { mentioned, but } \\
\text { applicable }\end{array}$ \\
\hline Wheeler 2015 & $\begin{array}{l}\text { Safety of Clinical } \\
\text { and Non-Clinical } \\
\text { Decision Makers in } \\
\text { Telephone Triage: } \\
\text { A Narrative Review } \\
\text { Journal of } \\
\text { Telemedicine and } \\
\text { Telecare }\end{array}$ & Strong & International & Qualitative & Rural based \\
\hline Baker 2015 & $\begin{array}{l}\text { Providing a lifeline } \\
\text { for rural doctors }\end{array}$ & Grey & Australia & Qualitative & $\begin{array}{l}\text { Not explicitly } \\
\text { mentioned, but } \\
\text { applicable }\end{array}$ \\
\hline $\begin{array}{l}\text { Hogenbirk } \\
2004\end{array}$ & $\begin{array}{l}\text { An Audit of the } \\
\text { Appropriateness of } \\
\text { Teletriage Nursing } \\
\text { Advice }\end{array}$ & Strong & Canada & Qual/Quant & Rural based \\
\hline
\end{tabular}




\begin{tabular}{|c|c|c|c|c|c|}
\hline Elsom 2013 & $\begin{array}{l}\text { Telephone survey } \\
\text { of service-user } \\
\text { experiences of a } \\
\text { telephone-based } \\
\text { mental health } \\
\text { triage service }\end{array}$ & Very Strong & Australia & Qualitative & Included \\
\hline Knight 2015 & $\begin{array}{l}\text { Gaps in } \\
\text { governance: } \\
\text { protective } \\
\text { mechanisms used } \\
\text { by nurse leaders } \\
\text { when policy and } \\
\text { practice are } \\
\text { misaligned }\end{array}$ & Strong & Australia & Qualitative & Included \\
\hline $\begin{array}{l}\text { DeCoster } \\
2010\end{array}$ & $\begin{array}{l}\text { Follow-through } \\
\text { after calling a } \\
\text { nurse telephone } \\
\text { advice line: A } \\
\text { population-based } \\
\text { study }\end{array}$ & Very Strong & Canada & Qual/Quant & Rural based \\
\hline Long 2015 & $\begin{array}{l}\text { Do "Virtual" and } \\
\text { "Outpatient" public } \\
\text { health tuberculosis } \\
\text { clinics perform } \\
\text { equally well? A } \\
\text { program-wide } \\
\text { evaluation in } \\
\text { Alberta, Canada }\end{array}$ & Strong & Canada & Quantitative & Included \\
\hline Beks 2018 & $\begin{array}{l}\text { 'When you're it': a } \\
\text { qualitative study } \\
\text { exploring the rural } \\
\text { nurse experience } \\
\text { of managing acute } \\
\text { mental health } \\
\text { presentations }\end{array}$ & Strong & Australia & Qualitative & Included \\
\hline Butler 2009 & $\begin{array}{l}\text { Managing medical } \\
\text { advice seeking in } \\
\text { calls to Child } \\
\text { Health Line }\end{array}$ & Very Strong & Australia & Qual/Quant & Rural based \\
\hline Ellis 2005 & $\begin{array}{l}\text { Health } \\
\text { infrastructure in } \\
\text { very remote areas: } \\
\text { An analysis of the } \\
\text { CRANA Bush }\end{array}$ & Grey & Australia & Qualitative & $\begin{array}{l}\text { Not explicitly } \\
\text { mentioned, but } \\
\text { applicable }\end{array}$ \\
\hline
\end{tabular}




\begin{tabular}{|c|c|c|c|c|c|}
\hline & $\begin{array}{l}\text { Crisis Line } \\
\text { database }\end{array}$ & & & & \\
\hline Tran 2017 & $\begin{array}{l}\text { Compliance with } \\
\text { telephone triage } \\
\text { advice among } \\
\text { adults aged } 45 \\
\text { years and older: An } \\
\text { Australian data } \\
\text { linkage study }\end{array}$ & Very Strong & Australia & Qual/Quant & $\begin{array}{l}\text { Very } \\
\text { remote/rural }\end{array}$ \\
\hline Mazza 2006 & $\begin{array}{l}\text { 'I'm just ringing for } \\
\text { some advice...'-- } \\
\text { issues concerning } \\
\text { GP advice lines. }\end{array}$ & Grey & Australia & Qualitative & Included \\
\hline Ahmad 2012 & $\begin{array}{l}\text { What is needed to } \\
\text { implement a } \\
\text { computer-assisted } \\
\text { health risk } \\
\text { assessment tool? } \\
\text { An exploratory } \\
\text { concept mapping } \\
\text { study }\end{array}$ & Good & Canada & Qualitative & $\begin{array}{l}\text { Not explicitly } \\
\text { mentioned, but } \\
\text { applicable }\end{array}$ \\
\hline Alami 2018 & $\begin{array}{l}\text { The challenges of } \\
\text { a complex and } \\
\text { innovative } \\
\text { telehealth project: } \\
\text { A qualitative } \\
\text { evaluation of the } \\
\text { eastern Quebec } \\
\text { telepathology } \\
\text { network }\end{array}$ & Strong & Canada & Qual/Quant & $\begin{array}{l}\text { Not explicitly } \\
\text { mentioned, but } \\
\text { applicable }\end{array}$ \\
\hline Nataraj 2020 & $\begin{array}{l}\text { Emergency } \\
\text { department } \\
\text { referrals from a } \\
\text { provincial medical } \\
\text { call centre: Is it } \\
\text { more than just } 1 \text { - } \\
800 \text {-go-to-emerg? }\end{array}$ & Good & Canada & Quantitative & Included \\
\hline $\begin{array}{l}\text { Fitzsimon } \\
2020\end{array}$ & $\begin{array}{l}\text { Providing } 24 / 7 \\
\text { healthcare for all } \\
\text { during the COVID- } \\
19 \text { pandemic }\end{array}$ & Grey & Canada & Qualitative & Included \\
\hline Ding 2020 & $\begin{array}{l}\text { Wearable Sensing } \\
\text { and Telehealth } \\
\text { Technology with } \\
\text { Potential } \\
\text { Applications in the } \\
\text { Coronavirus }\end{array}$ & Good & International & Qual/Quant & Included \\
\hline
\end{tabular}




\begin{tabular}{|c|c|c|c|c|c|}
\hline & Pandemic & & & & \\
\hline COACH 2015 & $\begin{array}{l}\text { Canadian } \\
\text { Telehealth Report }\end{array}$ & Good & Canada & Qual/Quant & Includeo \\
\hline $\begin{array}{l}\text { Desborough } \\
2020\end{array}$ & $\begin{array}{l}\text { Australia's national } \\
\text { COVID-19 primary } \\
\text { care response }\end{array}$ & Grey & Australia & Qualitative & Includec \\
\hline
\end{tabular}

